\title{
Vania Cárdenas, Tierras blancas de sed. Cartografía oral del valle de Huasco, Valparaíso, Ediciones Inubicalistas, 2020
}

\author{
Nelson Arellano Escudero
}

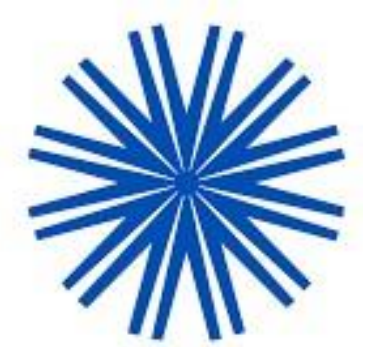

Vania Cárdenas Muñoz ha sido autora, previamente, de El orden Gañán: historia social de la policía de Valparaíso (Editorial Escaparate, 2013). Este antecedente es relevante para comenzar el recorrido por estas Tierras blancas de sed. Se trata de una cartografía con espesura sensible donde se combinan formas de aproximación que construyeron una narrativa de los sujetos relevantes para la comprensión del tiempo y los giros epocales.

El libro, luego de los agradecimientos y antes de presentar el índice, se abre al tiempo y la conciencia con el segmento del mapa de la Provincia de Atacama dibujado por Fuentes para la cuarta edición de la Geografía descriptiva de la República de Chile a cargo de Enrique Espinoza. Toda una declaración de posición y disposición.

La organización del libro se compone con unas palabras iniciales a modo de prólogo que establecen las coordenadas en las que transitarán sus 3 capítulos y epílogo, bien acompasados con el glosario y la selección de fuentes.

El capítulo primero, de "Asentamientos, trabajos y recursos en el Valle del Huasco" urde la inserción investigativa de corte etnográfica gracias a la que podemos internarnos en las memorias y significados del escenario en el que los acontecimientos, en su tragedia y su comedia, tuvieron lugar en sitios de una minería que no entran fácilmente en los registros nacionales -a decir verdad, los registros metropolitanos del centralismo- como son El Zapallo, Quebradita, Agua del Medio, La Liga, Los Choros, Chañaral de Aceituno o El Morado.

La definición de la escala es crucial para la puesta en valor de la tragedia de los accidentes, donde las estadísticas no cuentan mientras que el impacto emocional que tuvo en los protagonistas llega hasta nuestras manos a través de estas letras más de medio siglo después. En ello coincidimos con la autora en 
la pertinencia de acogerse a la obra de Alessandro Portelli para abordar el insondable registro de la memoria. Esta misma línea de análisis releva la posición del trabajo en la Majada, la agricultura y la vida doméstica no remunerada o con pagos subvalorados, así como la vida escolar, usualmente breve, de niños mientras que a las niñas les era prohibida o aún más limitada esa experiencia, debido al trabajo infantil como uso y costumbre a mediados del siglo XX. Una vida que era considerada marginada de la sociedad por el Gobernador de Freirina en mayo de 1965 y que era, en su opinión, preferible erradicar (pág. 37).

El segundo Capítulo produce las "Cartografías del Valle del Huasco: las voces de la historia oral" que permite conocer aspectos de la cultura transhumante en el Valle del Huasco y emerge una composición de las memorias sueltas que, en su reunión, facilitan la comprensión de la memoria emblemática y la necesidad de establecer la valorización de un modo de vida enfrentado a la crisis civilizatoria del proyecto de la modernidad.

Aquellas voces de la historia oral revelan las circunstancias en que se habitaron y despoblaron sitios al son de los eventos de la economía nacional y mundial, gestando procesos de reconstrucción, menos de materialidad que de identidad, en duras circunstancias de abandono e incertidumbres de la década de 1970. Tiene sentido aquí relevar de manera especial la enorme contribución de las mujeres para sostener esta conformación cultural en crisis y que, pese a todo, logró sostenerse, aunque el tiempo presente del siglo XXI vuelve a cernir esos aires de cambio -que gustan de anunciar épocas de fin de era- que, hemos visto, la historia reconduce a lugares y formas que, en realidad, ni eran tan distintos ni tampoco estaban determinados.

Entre los capítulos segundo y tercero el libro introduce un archivo fotográfico rico, variado y valioso que merece un estudio de visualidades profundo. Por ejemplo, en la fotografía número 15 se retrata a un adulto y 6 niños, quedando al parecer un séptimo fuera de cuadro, puede ser caracterizado por la precariedad de su equipamiento de protección personal consistente en un casco tipo Brodie y una lámpara minera, aparentemente, de carburo tipo Justrite. La fotografía no está fechada. El emplazamiento se atribuye al Mineral Santo Domingo El Morado y en el fondo de la imagen de aprecian estructuras de madera que parecen ser un área de montaje para las operaciones en el exterior de la bocamina. La colección de 37 fotografías ofrece una excelente oportunidad de apertura a nuevos detalles de las historias que combinan los ensamblajes de las personas, sus objetos y los ambientes que fueron retratados. 
El tercer capítulo está destinado a "Las/os protagonistas de la historia" que, podríamos discutir, contraviene la condición subalterna a la que se proponía subsumirles en las palabras preliminares. En esta fase de la narración los actores sociales humanos que han sido relevados se presentan en la constelación de arrieros, mineros, crianceros, hombres y mujeres que, como señala la propia autora: "reclaman un lugar en el patrimonio de este valle".

Los catorce testimonios que se disponen en el capítulo, acompañados de registros gráficos íntimos, coronan la etnohistoria poliédrica que, además de su espesura sensible, concreta una descripción densa a la que se fueron añadiendo recursos de la Historia, las Ciencias Sociales y la literatura nacional y local.

En el Epílogo Vania nos deja una declaración con la reunión de los tiempos, esos tiempo suspendidos en Octubre de 2019, que releva a los protagonistas en "todos los rincones de Chile" que han estado fuera de la escena pública.

La bella y cuidadosa edición del libro materializado en un excelente papel Bond Ahuesado es una magnífica invitación a leerlo desde la ilustración de su portada que pone en primer plano una pirca sobre la que descansan, solitarias, una picota y una pala, ante un fondo que consiste en un paisaje de valle dominado en la lejanía por los desnudos cerros del Valle de Huasco.

Tierras blancas de sed. Cartografía oral del Valle de Huasco es una contribución relevante para los estudios de la Historia regional, sin duda, pero también para los recorridos investigativos interdisciplinarios y una base valiosa para las indagaciones transdisciplinares que, entre otras preguntas, aborden los saberes compartidos como un paso necesario ante la demanda por información acera del Sujeto Político humano y sus modos de vida. Vania Cárdenas Muñoz nos presenta en un territorio bien delimitado el mapa de un universo que a penas comenzamos a conocer. 